\title{
Palliative Medicine
}

http://pmj.sagepub.com/

Teenagers' and parents' views on a short-break service for children with life-limiting conditions: A qualitative study

Veronica Swallow, Tracey Forrester and Ann Macfadyen

Palliat Med published online 7 April 2011

DOI: $10.1177 / 0269216311401947$

The online version of this article can be found at:

http://pmj.sagepub.com/content/early/2011/04/07/0269216311401947

Published by:

๑SAGE

http://www.sagepublications.com

Additional services and information for Palliative Medicine can be found at:

Email Alerts: http://pmj.sagepub.com/cgi/alerts

Subscriptions: http://pmj.sagepub.com/subscriptions

Reprints: http://www.sagepub.com/journalsReprints.nav

Permissions: http://www.sagepub.com/journalsPermissions.nav 


\title{
Teenagers' and parents' views on a short-break service for children with life-limiting conditions: A qualitative study
}

Palliative Medicine $0(00)|-| 1$

(C) The Author(s) 2011 Reprints and permissions: sagepub.co.uk/journalsPermissions.nav DOI: $10.1|77 / 02692163| 1401947$ pmj.sagepub.com

\author{
Veronica Swallow University of Manchester, UK; University of Newcastle upon Tyne, UK \\ Tracey Forrester Northumbria University, UK \\ Ann Macfadyen University of Manchester, UK; Northumbria University, UK
}

\begin{abstract}
Few opportunities exist outside the home for children and teenagers with life-limiting conditions to have a break in a setting specifically designed and adequately staffed and resourced to meet their complex clinical, practical and emotional needs; until recently provision focused primarily on providing respite for parents/carers. Based on policy recommendations, a short-break service was established with the aim of working in partnership with families and voluntary and statutory agencies to provide a fun break for children and teenagers with life-limiting conditions and complement the range of services available. This qualitative study used interviews and focus groups to determine teenagers' and parents' views of the service. Three themes emerged: accessibility and communication; needs and boundaries; and shaping the service. Teenagers enjoyed regular planned residential breaks, access to skilled staff and bespoke facilities to support their needs, opportunities to meet others with life-limiting conditions and fun time away from home, thereby giving parents peace of mind, a regular planned break from care-giving, opportunities to meet other parents and to spend exclusive time with their other children. If specialist short-break services become part of the national range of services available, children and teenagers with life-limiting conditions and their parents and siblings could all benefit.
\end{abstract}

\section{Keywords}

Children and teenagers, life limiting, life shortening, respite, short breaks

\section{Introduction}

Parents of children with life-limiting conditions in the North of England in 1995 recommended provision of specialist respite care:

... for the whole family in a small self-contained unit.

Souter et al., ${ }^{1}$ p.40.

Although the term 'respite' may have negative connotations (respite services tend to focus on provision for carers who are seen to be managing intolerable situations ${ }^{2}$ ), parents do not necessarily regard their child as a 'burden'. ${ }^{3}$ Nevertheless, children and teenagers with life-limiting conditions, including those at the palliative care stage, often require specialist clinical support from a multi-disciplinary team working in partnership with families and leisure activities with peers on a regular and emergency basis. There is, therefore, a need for advanced care planning and provision of short breaks for children, teenagers and parents, ${ }^{4-6}$ rather than focusing on respite for parents as a last resort; however, this need remains unmet in some areas. ${ }^{7-12}$ Clinicians and researchers increasingly advocate the provision of specialist respite care for families:

[services] have concentrated on curative medicine or health-promotion: meaning those who experienced a

Corresponding author:

Dr Veronica Swallow, School of Nursing, Midwifery and Social Work, University of Manchester, University Place, Oxford Road, Manchester MI3 9PL, UK

Email: veronica.swallow@manchester.ac.uk 
long-term disability, especially where death was expected, have to 'take a back seat' Craft, ${ }^{13}$ p.193.

Against this background a specialist short-break service (the service) for children and teenagers ( $0-18$ years) with life-limiting conditions requiring high levels of specialized care $^{14}$ was established in 2003 to:

... give a child or person(s) they live with a quality experience, a good time and as a consequence give them all a break.

Most disabled children and teenagers like and need regular breaks, ${ }^{15,16}$ 'time out' and 'fun'; for parents/ carers it is important to have regular 'short breaks'. 17 Sometimes this means a break together and sometimes teenagers choose a break away from their families to 'chill out' and meet new friends. When a child or teenager has a life-limiting, progressive condition, an environment is also needed that provides nursing care, medical care, physiotherapy, social work, play therapy, occupational therapy and clergy support (that is registered by the National Care Standards Commission), creating a 'home from home' environment and ensuring that they can be supported by a team that provides 24 hour, seven days a week residential care. ${ }^{1}$

UK policies increasingly highlight the vital need for short-break services for disabled children, ${ }^{5}$ telling us families want, amongst other things, more respite. ${ }^{18,19}$ Significant service investment is now in place to support specialist short-break services and appropriate healthcare. ${ }^{20}$ Nevertheless, the evidence base for development/organization of such services is weak and limited data exist to demonstrate best practice. .,21,22 $^{2}$ Therefore, we conducted a qualitative study of staff and families' views of the service. This paper focuses on the accounts of parents and teenagers using the service at the time of the study. The need to involve children and teenagers with life-limiting conditions in health-care research is increasingly recognized and the methodological challenges of this are acknowledged. ${ }^{7-9,19,23-26}$

\section{Method}

We used a qualitative approach to obtain participants' in-depth views of ${ }^{27,28}$ the service in relation to skill mix of staff, partnership working, access to leisure activities, opportunities for independence and peer support.

\section{Ethical considerations and rigour}

Appropriate approvals were obtained. Study information was presented according to participants' age and level of understanding. Written consent was obtained from parents, and verbal consent from teenagers after researchers read information sheets/consent forms with them. ${ }^{29-33}$ Data were collected from parents by researchers previously unknown to them, thereby reducing the possibility of socially desirable responses, ${ }^{34}$ and from teenagers by one unknown researcher and one they knew, who understood their communication styles, To ensure trustworthiness/credibility we incorporated reflexivity into the data management process. $^{34}$ Because of the small sample size involving only one site, information about diagnoses that could lead to participant identification is omitted from the reporting.

\section{Sample}

Using a convenience sample ${ }^{34}$ we invited parents of the 16 children and teenagers using the service at the time of study and the five teenagers (aged 14-18 years) with sufficient (but limited) communication, to participate independently. The remaining 11 children were ineligible because of profound communication difficulties, but parents' accounts acted as proxy. The resulting sample was five teenagers, 15 mothers and five fathers (representing 15 families). On average families booked short breaks 10 times a year.

\section{Data collection}

Data were collected through five individual interviews and four focus groups with parents, and two focus groups with teenagers. To minimize families' inconvenience, teenager groups took place during a booked short break. Focus groups offer a valuable, versatile, interactive and fun method for use with teenagers when seeking their views; ${ }^{35}$ they were conducted in the teenage room by TF who understood their communication styles, and AM who did not know them but had prior experience of accessing teenagers' views. ${ }^{28}$ Groups were supported by a topic guide and were as interactive as possible to maximize opportunities for individual communication (Table 1).

Fans and drinks were provided; when listening to teenagers, it is important to use communication strategies that are acceptable to them. ${ }^{28,36}$ Prompts (such as previously obtained photographs of the teenagers involved in activities at the service) were available but not required. Discussion lasted 30-60 minutes; signs of restlessness and requests for another drink were taken as an indication that they had said enough.

Focus groups with parents (lasting 60-90 minutes) were conducted by VS and AM in a quiet room in the service, while individual interviews were undertaken by VS in parents' homes. Choice was offered as some may prefer the interactive nature of focus groups where 
Table I. Topic guide for teenagers' focus groups

\section{Introduction and background to the study}

\section{Knowledge and understanding of the service}

What did the child/young person know about the service before their first visit?

How was information given and by whom?

Having experienced the service, how would the child/young person describe the service to his/her friend?

Any anxieties/concerns about using the service

Views and experiences in relation to the skill mix of staff

General e.g. what makes a good worker?

Qualities e.g. what should they be like?

Skills e.g. what should they be good at?

Knowledge e.g. what should they know about?

Experience e.g. what kind of things should they have done before?

Any particular concerns or anxieties

Impact 'short breaks' have had on access to leisure activities

How would the child/young person describe the leisure opportunities at St Oswald's?

Any difference in opportunities to access leisure activities since joining the service?

Views on what makes the service 'specialist'

When did the child/young person first hear about the service?

How would they describe their feelings experienced when the service was first mentioned?

Suggestions on how the service could be improved

Improve the information about the service e.g. age appropriate, designed by children/young people, different methods to include video, pictures, symbols

Access to a wider choice of leisure activities

Describe what the child/young person enjoys most/least about the service

other peoples' comments stimulate reflection about the issue under discussion, while others may prefer individual interviews in the privacy of their own homes to discuss this potentially sensitive topic. ${ }^{37,38}$ All were held at a time convenient to participants. Discussion was based on a topic guide designed to stimulate purposeful conversation, gain insights and generate ideas in order to pursue topics in greater depth ${ }^{39,40}$ (Table 2). All discussions were tape recorded/transcribed; personidentifiable detail was removed.

\section{Data analysis}

Data were analysed using framework analysis, ${ }^{38,41}$ which is systematic, thorough and grounded in the data but flexible and enables easy retrieval of data to show others. It allows between and within case analysis and has an overt policy orientation (Green and Thorogood, ${ }^{27}$ p.186). Transcripts were analysed through: ${ }^{37}$ (1) familiarization; (2) identification of a theoretical framework; (3) indexing; (4) charting; and (5) mapping/interpretation. This involved (1) all authors closely readings transcripts following which (2) a coding framework of four themes and 30 sub-themes was jointly developed, (3) the framework was applied (manually) to all transcripts, and (4) it was 'lifted' to a Microsoft Excel spreadsheet for charting where key quotations were labelled and identified (Table 3) for later retrieval when reporting.

The authors then worked independently (5), searching for patterns within the data, mapping connections and seeking explanations for patterns before comparing/discussing these collectively until achieving a consensus. This process enabled us to consider relationships between codes. ${ }^{27,37,38}$ Stages (4) and (5) were facilitated by colour coding parent/teenager datasets and finally, findings were interpreted and re-analysed within the framework to distil the themes and sub-themes (Figure 1). Findings were fed back to and discussed with participants.

\section{Findings}

This section juxtaposes quotations with discussion to illustrate the emergent themes from teenagers' and parents' perspectives. Within the theme accessibility and communication, teenagers' accounts of equipment and parents' accounts of the service environment, communication and accessing the service are presented. In the theme needs and boundaries, teenagers' accounts include the importance of choice, while parents focused on balancing opportunities, stages of need, transition to adult services and raising others' awareness about the service. In the theme shaping the service, teenagers 
Table 2. Topic guide, parent interviews

\section{Knowledge and understanding of the service}

- How did you first find out about the service?

- What did the child/young person know about the service before their first visit?

- How was information given and by whom?

- Having experienced the service, how would you/the child/young person describe the service to his/her friend?

- Any anxieties/concerns about using the service

Views and experiences in relation to the skill mix of staff

- General e.g. what makes a good worker?

- Qualities e.g. what should they be like?

- Skills e.g. what should they be good at?

- Knowledge e.g. what should they know about?

- Experience e.g. what kind of things should they have done before?

- Any particular concerns/anxieties

Impact 'short breaks' have had on access to leisure activities

- How would you/the child/young person describe the leisure opportunities?

- Any difference in child's/young person's opportunities to access leisure activities since joining the service?

- Any difference in your own leisure opportunities?

Views on what makes the service 'specialist'.

- E.g. facilities, philosophy, staff skill mix

Views on involvement in decision making

- When did the child/young person first hear about the service?

- How would you describe your feelings when the service was first mentioned?

- What do you think are important factors in involving children/parents/siblings in decision making?

Suggestions on how we can improve the service

- Improve the information about the service e.g. age appropriate, designed by children/young people, different methods to include video, pictures, symbols

- Access to a wider choice of leisure activities

- Describe what you/the child/young person enjoys most/least about the service

discussed the physical environment and staff, while parents emphasized practical, professional and organizational issues (Figure 1).

\section{Accessibility and communication}

\section{Equipment}

Teenagers thought it was important to have the right equipment at the service, as one boy explained: 'we need things that work'. Teenagers' main focus was on powered wheelchairs, as they are their main mode of transport and the key to independence. One wanted to use a powered chair as soon as possible to keep up with friends, yet some mothers perceived powered mobility as a 'last resort', but eventually appreciated that the increased independence enabled by a powered chair positively affected others' attitudes towards their child, thus helping them develop relationships.

\section{Atmosphere and perceptions}

The atmosphere was very important. Parents compared this and other services:

It's different here because staff [at other service] are not medically trained so when she [daughter] comes here we can relax, have a nice break.

The atmosphere was described by parents as calming and staff as:

... lovely with the children, they do genuinely take an interest in them. 
Table 3. Extract from chart produced for the theme needs and boundaries

\begin{tabular}{|c|c|c|c|c|}
\hline $\begin{array}{l}\text { Interview no./ } \\
\text { participant. }\end{array}$ & Choice & Balance/opportunities & $\begin{array}{l}\text { Stages of need and } \\
\text { transitions }\end{array}$ & Raising awareness \\
\hline I4/mother & $\begin{array}{l}\text { Would be quite nice if they } \\
\text { matched up children with } \\
\text { similar needs on specific } \\
\text { days p7 }\end{array}$ & $\begin{array}{l}\text { They [a group of young } \\
\text { people] met all the } \\
\text { [local team] football } \\
\text { players and got auto- } \\
\text { graphs, I could not access } \\
\text { that. They have funds to } \\
\text { go places and get com- } \\
\text { plementary tickets p3 }\end{array}$ & $\begin{array}{l}\text { He will hopefully go to uni- } \\
\text { versity, get direct pay- } \\
\text { ments and employ own } \\
\text { carer plo }\end{array}$ & \\
\hline 7/young person & $\begin{array}{l}\text { l'd spend most of my week- } \\
\text { end in bed if I didn't } \\
\text { come here p7. }\end{array}$ & & & \\
\hline 5/young person & & Go to the pictures, bowling & & \\
\hline 3/father & $\begin{array}{l}\text { I think boys relate better to } \\
\text { men. He's quite heavy to } \\
\text { take in the pool, it's } \\
\text { easier for a male, a lad } \\
\text { wants a young girl or a } \\
\text { man, not a lady p7 }\end{array}$ & $\begin{array}{l}\text {.. [to meet other par- } \\
\text { ents] so we could contact } \\
\text { them to make sure that } \\
\text { we get two or three } \\
\text { teenage boys together at } \\
\text { the same time so they } \\
\text { can talk about football } \\
\text { and computer games, } \\
\text { that's really important } \\
\text { pl2. }\end{array}$ & $\begin{array}{l}\text { I don't ever look forward } \\
\text { more than six to nine } \\
\text { months, I don't think I } \\
\text { can, I'm quite sure it [the } \\
\text { future] will be addressed } \\
\text { at the appropriate times } \\
\text { pI5. }\end{array}$ & $\begin{array}{l}\text { It is not like the hospice I } \\
\text { expected... must be } \\
\text { different to your average } \\
\text { hospice... my dad was in } \\
\text { an adult hospice and I } \\
\text { know that is totally dif- } \\
\text { ferent } p 3 \text {. }\end{array}$ \\
\hline
\end{tabular}

The multi-disciplinary team [including nursing, medicine, physiotherapy, clergy, social work and play therapy] and the trust between staff and children was a major source of parental discussion:

He has such a good rapport with [staff] ... I think he's really happy-it's such a relief!

\section{Communication}

Staff-family communication was a recurrent theme. Several parents liked being invited to stay on the first visit to show staff how they care for their child, although:

... in the beginning we were asked loads of upsetting questions...

She later acknowledged these were necessary questions. Parents spoke positively about the fact that children's needs are reassessed at each visit, giving them opportunities to update staff on care-giving changes:

... the doctor is always on hand ... to check they're up to date on medication.

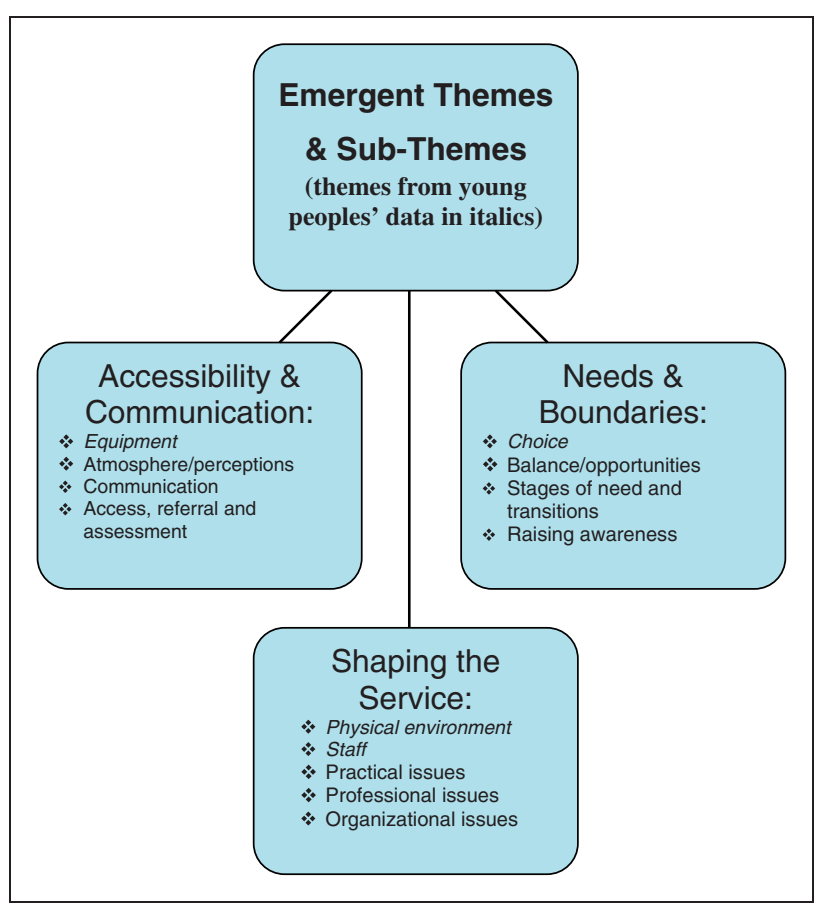

Figure I. Emergent themes and sub-themes. 
Parents were pleased staff phoned ahead to ask which leisure facilities and food children/teenagers would like on a short break, as teenagers at home had few opportunities to participate in activities that healthy teenagers enjoy. Parents suggested staff keep a diary for children/ teenagers who forgot what they had done during a short break or had communication difficulties.

Communicating with teenagers about death was a theme in parents' focus groups, with mixed views reported. Some wished to protect their child from knowledge of their own prognosis or another child's death, others did not want staff discussing prognosis with their child; one couple noted that their son tried to protect them from the need to talk about his prognosis.

\section{Access, referral and assessment}

When asked if anything could be done to improve the service, teenagers focused on access and having fun (Table 4).

Parents on the other hand focused on referral/ assessment and were concerned about delays in completing initial assessments to access the service. The service offered contingency (emergency) days, but one mother was concerned a place might be unavailable at short notice.

\section{Needs and boundaries}

\section{Choice}

Teenagers chose to use the service because of the following: the plasma screen TV; someone they knew used it and enjoyed it; an opportunity to have a break on their own away from the family and liked to choose what they did during a short break, including what time they got out of bed and which activities/outings they wanted. Most liked being telephoned before a stay to ask what they wanted to do. Compared to being at home there was better access to leisure activities.
One said:

I'd spend most of my weekend in bed if I didn't come here.

Teenagers described activities such as hide and seek, treasure hunts, playing on the computer/internet, singing and listening to music. This reflects the service aim to promote an inclusiveness agenda for activities through staffing levels (one to one), accessible transport and volunteer drivers. Staff, unlike parents, could offer undivided attention.

\section{Balance/opportunities}

The service philosophy balanced an aim to offer leisure activities with opportunities to have fun regardless of physical/cognitive limitations. Parents valued meeting other families using the service.

Accessing the service provided parents with opportunities to enjoy aspects of family life that are usually impossible, meaning parent(s) could have much needed rest/leisure time and siblings could enjoy time with parents alone, one mother explained:

I can lie in bed on a Saturday knowing I haven't got to come down stairs and put him on the toilet

Another could offer their healthy daughter choice while their son has a short break:

In a restaurant, there were stairs up to another level [where their daughter wanted to go] so we asked to go up [this would be impossible with their son's wheelchair], we don't tell [son] but, it's important his sister has this time.

Parents found it reassuring that their child was happy to use the service:

He'll go anytime alone, a massive thing for us ... there's nowhere else he'll go alone.

Table 4. Young people's suggestions

(1) Change the grass area at the front of the house to a tarmac area for wheelchair football, hockey and general access across the garden.

(2) Decorate the teenage room to make it different from the children's area, make it look more like a 'den' with more colour and more 'stuff' in it.

(3) Create a sitting area similar to that of a cinema/drive in movie for watching DVDs, etc.

(4) Have an area within the unit that they could go to without staff. This could be a room to 'chill out' and get away from staff and other children.

(5) More computer games...... 'the games are ancient'.

(6) Decorate the bathrooms, 'the blue feels cold'. 
In addition, parents liked the way staff welcomed the whole family:

We take him in at $2 \mathrm{pm}$, stay until $8 \mathrm{pm}$ before we leave him, his sister loves it.... I think it's not so much for me it's for the children.

Siblings' needs were a source of much discussion by parents; one couple felt sorry for their daughter who:

Is very caring but also likes time alone with us.

Some parents would not take holiday and leave their child at the service because 'He might think I'm punishing him if leave him to go on holiday', while others took the opportunity to leave their child in a place and with people they had confidence in:

Last time [son was having a short-break] I went away with my husband, which is unique for us.

\section{Stages of need and transitions}

Having at last found a service matching their child's needs, some parents shared their fears for their child's future because of shortened life expectancy:

If they're going to live for another 50 years then I'd think they need to go somewhere else [at 18] . . but [as it is] the last thing you want is giving them to someone else.

In contrast some parents were philosophical about the future.

\section{Raising awareness}

Parents' wanted to raise awareness of the difference between their expectations of the service and the reality. They initially understood it was a 'children's hospice' so a place to die, so attitudes were coloured by connotations of the word 'hospice':

Mum: When I first heard about it [the service] I wasn't keen, was thinking there'd be older people there, but when we went to see it...

Dad:... oh a lovely place.

\section{Shaping the service}

\section{Physical environment}

One teenager said:

When first came I said I wanted to live here!
Others liked the fact they could share activities because of the design, layout and size of the building:

...two wheelchairs can race down a corridor side-byside and it's easy to move from room to room.

All enjoyed the unique experience and freedom the space allowed them.

\section{Staff}

On the whole teenagers did not report any differences between the skills of individual staff; one noted that nurses could give drugs, another that it did not matter:

... as long as they could do the basics such as using the hoist.

One teenager thought all staff should be able to do everything. Staff members' interpersonal skills seemed most important to teenagers:

\footnotetext{
'A sense of humour', 'being a nice person', respect [for teenagers], 'not getting angry', 'able to have fun' and 'not getting embarrassed' [referring to personal care or talking about sensitive issues].
}

Some teenagers preferred a younger carer and some thought it was better for boys to have a male carer.

\section{Professional, practical and organizational issues}

Parents' valued the fact there were always qualified staff on duty with experience in caring for their children's complex needs; this promoted their confidence in staff. Parents preferred the service over others they knew because they believed staff members were competent in all areas of care. The following quotation is typical:

They are all trained here... have worked with children with special needs and are just so lovely with him so you haven't got any worries, or medical concerns ... in hospital you're left in a cubicle [whereas here] someone's with him all the time... better than him being at home really! At least they [service staff] don't have to go to the kitchen or put the washing out... they're just fabulous.

Some parents spontaneously commented that the presence of trained doctors, nurses and physiotherapists made it a specialist service, while one parent said:

I think the skill mix is quite healthy really. 
Parents also believed:

... you've got to know what you are doing to look after someone like that...[here] they're able to deal with more intensive medical needs whereas at [other hospice facility] they weren't able to cope with certain aspects of care, such as when he had a seizure and aspirated they couldn't do suction.

Most parents realized that:

... with so many conditions coming in it is a big melting pot, can't expect the staff to have a really good grounding in all conditions.

Nevertheless, parents believed that the multi-skilled nature of the team meant there was always sufficient expertise available to review children's clinical conditions, monitor them and their responses over 24 hours and give feedback to the community team. One father explained:

... the staff found some way to change the liquid feed that was better than at home.

Teenagers and parents were very satisfied with most organizational aspects of the service; some suggestions for continued development included the following.

\section{Day care provision}

Because of the excellent facilities and the trust engendered between staff and families, parents advocated the additional provision of booked day care facilities:

... [day care] would be a good idea because there is many a time we are stuck in [at home]... If day care was available we could go off to do our shopping.

\section{The future}

Mothers and fathers would like access to relaxation and aromatherapy, while other parents suggested a newsletter aimed at the children and siblings because siblings like to get involved, and more flexibility about drop off and pick up times. Because laundry facilities were unavailable at the service, parents often found it expensive to provide enough clothes for a short break:

... they [staff] don't wash clothes so you have to plan. It's alright if you have that amount of clothes, you know 14 pairs of trousers, I had to go out and buy him trousers with zips all the way $\ldots £ 30$ a pair!

\section{Discussion}

Using qualitative methods to obtain in-depth accounts, ${ }^{34,38}$ we sought teenagers' and parents' views on using the service. Framework analysis entailed comparison within and between cases so we were able, as far as was possible, to compare parents' and teenagers' responses. This was facilitated in particular by the fourth stage (charting), which involved rearranging data according to its thematic content, as demonstrated in Table 3, and summary examples in charts are referenced back to the original statement. In stage 5, mapping and interpretation enabled us to look at relationships between themes/sub-themes.

There is a particular need to involve disabled children in decision making and service review. If such opportunities are to be effective in enabling them to express their views, careful consideration needs to be given to the methods used and the environment involved. ${ }^{42}$ Focus groups might give young people more confidence in participating, ${ }^{43}$ particularly where they have little experience of one-to-one discussions with unfamiliar adults, and may facilitate memory prodding. We therefore organized the teenager discussions in such a way that participants had shared experiences of the service being evaluated, and initially asked them to describe their experiences before moving to more evaluative questions.

Teenagers reported no preferences about staff members' clinical skills, the most important issue being interpersonal skills. This was in contrast with others' accounts, ${ }^{44,45}$ where disabled children placed similar value on technical and interpersonal factors. Most parents in our study, however, did value professionals' technical and interpersonal skills with parents' accounts corresponding with the notion of guarded alliance described by Robinson, ${ }^{46}$ who explored the development of health care relationships; these progressed through stages of naïve trust and disenchantment into guarded alliance, by which point families had become realistic about constraints on professionals and had developed strategies to help them make sense of and manage relationships with professionals. The parents in our study had many years experience of health care services; consequently, some had shifted their views of professionals away from a focus on the individuals' qualities towards an understanding of their part in the larger system. This wider perspective often demonstrates characteristics of the consumer model of partnership, ${ }^{47}$ where the professional acts in a consultative and instructional capacity, with the parent/child being very involved in decision making. This domain of partnership working was evident and is consistent with other models. ${ }^{48}$ In the current study partnerships were both a successful strategic 
intention by the service developers and an outcome of the service.

Because of their complex needs teenagers have limited access to activities other children take for granted, so access to leisure facilities seemed to be part of the attempt by teenagers in our study to achieve a degree of normalization. This corresponds with earlier work ${ }^{46}$ in which the basic strategy of normalizing charges society with providing resources and conditions under which disabled people enjoy as normal a life as possible. The underlying philosophy is motivated by humanitarian objectives, including the perceived right of individuals "not to be different'. ${ }^{25}$ The teenagers in our study were supported, as they grew and matured within the confines of their conditions, to enjoy activities that healthy peers enjoy, opportunities their parents are often unable to provide.

Visibility is important in peer relations because how noticeably different a child is often affects the response of others. ${ }^{49,50}$ Many teenagers using the service have highly visible needs (such as a naso-gastric tubes or a powered chair for independent mobility), so socializing with friends with similar needs was pleasurable. Other benefits of peer support included the opportunity to race along corridors side-by-side in wheelchairs and talk to each other in privacy, but in a safe, supported environment. For some, attending the service alone was the only opportunity to go somewhere without their parents, the possible exception being hospital stays when they are unwell.

\section{Study limitations}

Main study limitations include the absence of accounts from teenagers who lack verbal communication skills, the fact that data collection took place as a snapshot in time rather than representing changes over time and the fact one researcher was known to the families, therefore, it is possible this influenced their willingness to participate or the responses provided in focus groups.

\section{Implications for practice}

In general, a lack of access to everyday leisure activities may inhibit teenagers' potential to relate to others and take the risks necessary for optimum development. ${ }^{51}$ Furthermore, providing opportunities for normalization, play and a change of environment can be challenging, given the amount of equipment required by some children/teenagers with life-limiting conditions. Additional resources and personnel, such as those available in the service, can make such activities achievable for those normally denied them.
The importance of involving siblings in care for sick children has long been recognized; ${ }^{52}$ however, families have expressed concerns about the negative effect on siblings of a family member needing unusual amounts of care/attention. ${ }^{53,54}$ Parents in our study had similar concerns and the service provided reprieve from these negative effects.

A commitment to embed service user involvement within service delivery, and the fact that several teenagers' suggestions in the current study were implemented following the study, was important in communicating the outcomes of the young people's participation, a key principle in involving children and young people in decision making. ${ }^{55,56}$ These insights can inform service developers/providers. A high staff/child/teenager ratio enables staff to build up a trusting rapport with families that is valued by families and is consistent with recommendations from the Children's National Service Framework Outcome for Enjoying and Achieving. ${ }^{10}$ The specialist nature of the service meets policy recommendations that such children receive co-ordinated, high-quality family-centred care based on assessed needs, which promotes social inclusion and, where possible enables them to live ordinary lives. Nevertheless, a major requirement is the need to train sufficient staff to ensure they are competent to deliver safe care; staff training implications are significant. $^{6}$

\section{Implications for future research}

Future research involving data collection methods using video or computers could capture subtle aspects of communication between staff and children with limited communication, such as those in our sample. A longitudinal approach involving data collection at several time points with the same participants would enable analysis of different aspects of verbal/nonverbal interaction over time (for example, eye gaze direction, facial affect, gestures and vocalization) to help develop a coding framework for testing and use in other settings with children with life-limiting conditions.

\section{Conclusion}

Our findings could form the basis for wider policy and practice discussions about short-break services. ${ }^{18,20}$ The service supports a philosophy of family-centred care, with children's and teenagers' needs being the primary focus. The accounts presented provide valuable evidence of the way involvement with the service enhanced family members' lives, whilst identifying further ways services could meet their needs. 


\section{Acknowledgements}

We are very grateful to the families and staff who so willingly participated in and to the Burdett Trust who supported the study.

We gratefully acknowledge the support provided by the medical, nursing, physiotherapy, play-therapy, housekeeping staff and clergy, Mrs Val Bagnell and Mrs Pam Hepple while we were conducting the study.

\section{Funding}

This work was supported by a grant from the Burdett Trust.

\section{Competing interests}

The authors declare that they have no competing interests.

\section{References}

1. Souter J, Bond S and Craft A. Families of misfortune. Newcastle upon Tyne: Department of Child Health and Centre for Health Services Research, Newcastle University, 1995.

2. DoH. Inspecting for quality: guidance on standards for short-term breaks: a handbook for social workers and inspectors, users and carers. London: Department of Health, 1993.

3. Steele R and Davies B. Impact on parents when a child has a progressive, life-threatening illness. Int $J$ Palliat Nurs 2006; 12: 576-585.

4. Carlin $\mathbf{J}$ and Cramer H. Creative responses to changing needs? Fourth national survey of short break services for disabled children in the UK. York: Shared Care Network, 2007.

5. DfES/HMT. Aiming high for disabled children; better support for families. London: Department for Education \& Schools/HM treasury, 2007.

6. DCSF/DH. Aiming high for disabled children: short breaks implementation guidance. London: Department for Education \& Schools/Department of Health, 2008.

7. ACH. Children's hospice services throughout the UK. Bristol: Association of Children's Hospices, 2006.

8. Emond A and Eaton N. Supporting children with complex health care needs and their families - an overview of the research agenda. Child Care Health Dev 2004; 30 : 195-199.

9. Eaton N. 'I don't know how we coped before': a study of respite care for children in the home and while we were conducting this study hospice. J Clin Nurs 2008; 17: 3196-3204.

10. DoH/DfES. Every child matters-national service framework for children, young people and maternity services. Nottingham: Department for Education and Skills, 2004.

11. ACT/RCPCH. A guide to the development of children's palliative care services, 2nd ed. Bristol: Association for Children with Life-threatening or Terminal Conditions and their Families (ACT) and The Royal College of Paediatrics and Child Health (RCPCH), 2003.

12. ACT/RCPCH. A guide to the development of children's palliative care services, 3rd ed. Bristol: Association for
Children with Life-threatening or Terminal Conditions and their Families (ACT) and The Royal College of Paediatrics and Child Health (RCPCH), 2009.

13. Craft A. Children with complex health care needs supporting the child and family in the community. Child Care Health Dev 2004; 30: 193-194.

14. NDT\&CDS. An audit of respite and palliative care services in Tyne and Wear for children with complex needs. Newcastle upon Tyne: National Development Team and Council Disabled Service (NDT\&CDS), 2001.

15. Rodrigues $\mathbf{N}$ and Patterson JM. Impact of severity of a child's chronic condition on the functioning of twoparent families. J Pediatr Psychol 2007; 32: 417-426.

16. Sleed M, Beecham J, Knapp M, McAuley $C$ and McCurry N. Assessing services, supports and costs for young families under stress. Child Care Health Dev 2006; 32: 101-110.

17. DCSF. Parenting \& family support: guidance for local authorities in England. London: Department for Children, Schools \& Families, 2010.

18. DOH. Palliative care services for children and young people in England. London: Department of Health, 2007.

19. Rabiee P, Sloper P and Beresford B. Desired outcomes for children and young people with complex care needs, and children who do not use speech for communication. Health Soc Care Community 2005; 13: 478-487.

20. DOH. Better care: better lives: improving the outcomes and experiences for children and young people and their families with life-limiting and life threatening conditions. London: Department of Health, 2008.

21. Robinson C, Jackson P and Townsley R. Short breaks for families caring for a disabled child with complex health needs. Child Fam Soc Work 2001; 6: 67-75.

22. MacDonald $\mathrm{H}$ and Callery $\mathrm{P}$. Different meanings of respite: a study of parents, nurses and social workers caring for children with complex needs. Child Care Health Dev 2004; 30: 279-288.

23. Mitchell W and Sloper P. Information that informs rather than alienates families with disabled children: developing a model of good practice. Health Soc Care Community 2002; 10: 74-81.

24. Mitchell $\mathrm{W}$ and Sloper P. User-friendly information for families with disabled children: a guide to good practice. York: York Publishing Services, 2000.

25. Mitchell W and Sloper P. Quality in services for disabled children and their families: what can theory, policy and research on children's and parents' views tell us? Child Soc 2001; 15: 237-252.

26. RCPCH. A Guide to the participation of children and young people in health services. London: Royal College of Paediatrics and Child Health, 2010.

27. Green J and Thorogood N. Qualitative methods for health research. London: Sage, 2004.

28. Swallow V, Coad J and Macfadyen A. Involving children, young people and parents in knowledge generation in health and social care research. In: Nolan M, Hanson E, Grant G and Keady J (eds) User participation research in health and social care. Buckingham: OU Press, 2007. 
29. RCPCH. RCP (Royal College of Paediatrics and Child Health) Ethics Advisory Committee. Arch Dis Child 2000; 82: $177-182$.

30. Allmark P. The ethics of research with children. Nurse Researcher 2002; 10: 7-19.

31. Alderson P. Designing ethical research with children. In: Farrell A (ed.) Ethical research with children. Maidenhead: Open University Press, 2005.

32. UN. United Nations convention on the rights of the child. New York: United Nations, 1989.

33. Wright B, Aldridge J, Wurr K, Sloper T, Tomlinson H and Miller M. Clinical dilemmas in children with lifelimiting illnesses: decision making and the law. Palliat Med 2009; 23: 238-247.

34. Green $\mathbf{J}$ and Thorogood N. In-depth interviews. In: Green J and Thorogood N (eds) Qualitative methods for health research. London: Sage, 2004.

35. Gibson F. Conducting focus groups with children and young people: strategies for success. J Res Nurs 2007; 12: $473-483$.

36. Swallow V and MacFadyen A. Communication skills in nursing: effective qualitative research tools? Paediatr Nurs 2004; 16: 20-23.

37. Ritchie J and Spencer L. Qualitative data analysis for applied policy research. In: Bryman A and Burgess RG (eds) Analyzing qualitative data. London: Routledge, 1994.

38. Ritchie $\mathrm{J}$ and Lewis J. Qualitative research practice: a guide for social science students and researchers. London: Sage, 2003.

39. Legard R, Keegan $\mathbf{J}$ and Ward K. In-depth interviews. In: Ritchie $\mathbf{J}$ and Lewis $\mathbf{J}$ (eds) Qualitative research practice. London: Sage, 2003.

40. Bowling A. Research methods in health: investigating health and health services. Buckingham: Open University Press, 2002.

41. Swallow V, Newton J and Marshall C. How to manage and display qualitative data using 'Framework' and Microsoft Excel. J Clin Nurs 2003; 12: 610-612.

42. Franklin A and Sloper P. Supporting the participation of disabled children and young people in decision making. Child Soc 2009; 23: 3-13.

43. Punch S. Interviewing strategies with young people: the 'secret box', stimulus material and task based activities. Child Soc 2002; 16: 45-50.
44. Dunst C and Trivette C. Empowerment, effective helpgiving practices and family centred care. Paediatr Nurs 1996; 22: 334-343.

45. Law M, Hanna S, King G, Hurley P, King S, Kertoy M, et al. Factors affecting family-centred service delivery for children with disabilities. Child Care Health Dev 2003; 29: 357-366.

46. Robinson C. Managing life with a chronic condition: the story of normalisation. Qual Health Res 1993; 3: 6-28.

47. Cunningham $\mathrm{C}$ and Davis $\mathrm{H}$. Working with parents: frameworks for collaboration. Milton Keynes: Open University Press, 1985.

48. Danvers L, Freshwater D, Cheater F and Wilson A. Providing a seamless service for children with lifelimiting illness: experiences and recommendations of professional staff at the Diana Princess of Wales Children's Community Service. J Clin Nurs 2003; 12: 351-359.

49. Corker M and Shakespeare T. Disability/postmodernity: embodying disability theory. London and New York: Continuum, 2002.

50. Thompson RJ and Gustafson KE. Adaptation to chronic childhood illness. Washington, DC: American Psychological Association, 1996.

51. Langerman $\mathrm{C}$ and Worrall E. Ordinary lives - disabled children and their families: a guide for donors and funders. London: New Philanthropy Capital 2005.

52. Coleman V. The evolving concept of family-centred care. In: Smith L, Coleman V and Bradshaw M (eds) Familycentred care. Basingstoke: Palgrave, 2002.

53. Havermans T and Eiser C. Siblings of a child with cancer. Child Care Health Dev 1994; 20: 309-322.

54. Williams P, Williams A, Graff J, Hanson S, Stanton A, Hafeman $\mathrm{C}$, et al. Interrelationships amongst variables affecting well siblings and mothers of families of children with a chronic illness or disability. J Behav Med 2002; 25: 411-424.

55. Cavet $\mathbf{J}$ and Sloper P. Participation of disabled children making decisions about their lives and about service development. Child Soc 2004; 18: 278-290.

56. CYPU. Learning to listen: core principles for the involvement of children and young people. London: Children and Young People's Unit, Department for Children, Schools \& Family, 2001. 